tions had been performed in the period of non-secretion. A further investigation on $C$. acronius, the classical material of Hüfner, was therefore initiated in October. The fishes were caught at a possible secreting period. Ten specimens were caught near Unteruhldingen by gill nets at depths of $80-100 \mathrm{~m}$. Flotation measurements of the fishes gave buoyancy depths of $81-120 \mathrm{~m}$. All the specimens had an oxygen content ranging from $15 \cdot 2$ to $18 \cdot 3$ per cent. By mass spectrometry the argon/nitrogen ratio was measured, giving values of $90 \cdot 1-97 \cdot 0$ per cent of the air.

The relatively low oxygen content may indicate that the secreting period is terminated and the oxygen is being absorbed. The low argon content is in favour of this theory ${ }^{4}$.

The same process has been shown by experiments by me to occur in a physoclist fish (Gadus callarias). The fish was over-inflated with a mixture of $23 \cdot 4$ per cent nitrogen and 73.7 per cent oxygen. After 4 days the fish showed normal buoyancy with a gas content in the swim-bladder consisting of 95.5 per cent nitrogen and $3 \cdot 7$ per cent oxygen.

The results obtained indicate that the problem of secretion is common for the physostome and physoclist fishes, and the lack of a counter-current system does not exclude oxygen secretion.

Directorate of Fisheries,

Institute of Marine Research

Bergen, Norway. Jan. 7.

${ }^{1}$ Hüfner, G., Arch. Anat. Physiol. Lpz. Physiol. Abth. (1892).

"Saunders, R. L., Canad. J. Zool., 31, 547 (1953).

${ }^{3}$ Scholander, P. F., Van Dam, and Enns, T., Science, 123, 59 (1956)

4 Sundnes, G., Enns, T., and Scholander, P. F., J. Exp. Biol., 35, 671 (1958).

\title{
A Critical Test of Antigenic Relationships
}

A NEED has long existed for a simple, direct method for determining whether cross-reacting antigens are identical, or merely similar. Isolation and immunochemical characterization of individual antigens are often impossible. Measurement of precipitation or agglutinin titres, or of optimum proportions, are generally too crude to make distinction between identity and similarity possible, and may lead to confusing results ${ }^{1}$. Wodehouse ${ }^{2}$ has reported the method of cross-neutralization to be unsuited for antigenic analysis of allergens.

Introduction of the immuno double-diffusion gel plate technique by Ouchterlony ${ }^{3}$ apparently provided the required means for studying antigenic relationships. Complete fusing of precipitation bands of two antigens was taken to indicate antigen identity. Spur information was postulated, required and, in many cases, observed in antigen similarity without identity. Unfortunately, the conventional Ouchterlony technique can be deceptive. Its application has misled several investigators to postulate an identity of the major antigen(s) of the pollens of different species of grasses ${ }^{4-6}$.

Re-investigation of grass pollen antigen relationships by a new agar gel technique has produced conclusive evidence of antigenic similarity rather

\section{G. SUndnes}

(a)

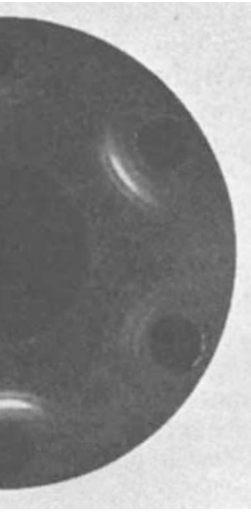

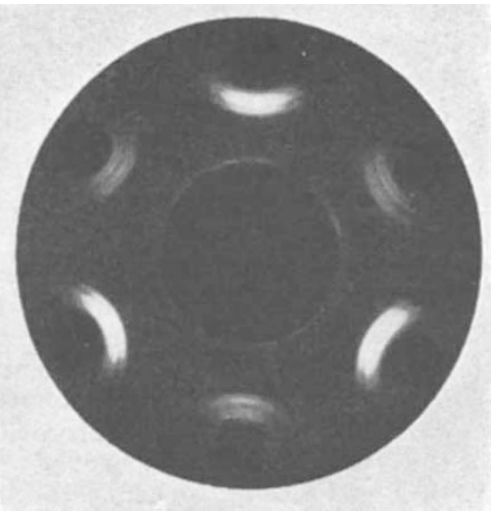

(b)
Fig. 1. Difference between precipitation bard intensitits of homospecific and cross(Bromus mollis) and cocksfoot (Dactylis glomerata) pollens, alternately, $a$, Antiserum to cocksfoot pollen in central well ; $b$, antiserum to brome pollen in central well

than identity. The method is based on a modification of a pattern and technique published previously ${ }^{7,8}$. It is simple and permits analysis of complex antigen mixtures as well as isolated antigens.

Patterns are cut in the agar with an accurately tooled cutting instrument (obtainable from the Shandon Scientific Co., London, S.W.7). Two plates are used for the comparison of two antigen solutions. In the central well of one plate is placed $0.2 \mathrm{ml}$. antiserum to one of the antigen solutions. The other plate similarly receives the antiserum to the other solution. Antibody gradient is established in the agar by incubating the plates with the sera at $37^{\circ} \mathrm{C}$. for $24-72 \mathrm{hr}$. Suitable concentrations of the two antigens are then placed in alternate circumferential wells in both plates and the plates incubated for a further $24 \mathrm{hr}$.

If the antigens are identical, the precipitation patterns at all wells are of equal intensity. Where a similarity without identity exists, alternate wells will show strong and weak precipitation band patterns, the positions being reversed in the two plates. In each plate the homospecific antigen gives strong bands, the related heterospecific antigen weak bands (Fig. 1).

The technique has been thoroughly tested on both complex and simple antigen systems. It has been found to be a critical and discriminating test of antigenic relationships. Extension of observations and theoretical considerations will be made the subject of a subsequent paper.

Photographs of the gel plates were made on the Lawson apparatus'.

\section{J. G. Feinberg Hazel Grayson}

Bencard Allergy Research Unit, Beecham Research Laboratories,

Betchworth, Surrey. Feb. 3.

"Kabat, E. A., and Mayer, M. M. " Experimental Immunochemistry" (Charles C. Thomas, 1948).

${ }^{2}$ Wodehouse, R. P., Ann. Allergy, 7, $172(1949)$

${ }^{3}$ Ouchterlony, 6., Ark. Kemi, Min. Geol., B, 26, 1 (1949).

4Augustin, R., Third Europeap Congr. Allergology, Abst., 1, 411 (1956)

${ }^{5}$ Augustin, R., Third International Congr. Allergology, Abst., C, 59 (1958).

${ }^{6}$ Wodehouse, R. P., Int. Arch. Allergy, 6, 65 (1955).

'Feinberg, J. G., Nature, 177, 530 (1956).

${ }^{s}$ Feinberg, J. G., Int. Arch. Allergy, 11, 129 (1957).

'Lawson, D. F., J. Photog. Sci., 5, 1 (1957). 